\title{
The future of the independent travel agent: the need for strategic choice
}

\author{
Lisa Harris* and Kevin Duckworth \\ Brunel University, $U K$
}

- This paper provides a contemporary example of the disruptive impact of new technology upon industry structure, through investigation into the ongoing viability of retail travel agents in an industry where technology is a key driver of change. The Internet has provided opportunities for major travel suppliers to target customers direct, potentially circumventing the traditional distribution channel through the travel agent.

- The data has been obtained from questionnaires, telephone interviews and personal experience of managing a tour operator and a travel agency, plus material from trade organizations such as ABTA. The objective was to identify potential opportunities for independent travel agents to respond to the challenges of disintermediation. The respondents provided a variety of perspectives as they included sales staff at the customer interface right through to key industry leaders.

- The paper concludes from the data analysis that the independent travel agent has a future provided it makes appropriate investment in technology, works closely with niche tour operators and creates competitive differentiation by focusing on specialist markets where core assets such as staff expertise can add value to the buying process and prevent the customer from 'going it alone'.

- The research indicates that the Internet is complementing rather than replacing existing business priorities in the travel industry. While sales of 'dynamically packaged'products through Internet technology are growing at the expense of more traditional bolidays, the latter still represents a significant aspect of the overall travel business. Travel agents can potentially add value in both of these business areas.

Copyright $(2005$ John Wiley \& Sons, Ltd.

\section{Introduction}

This paper investigates the future of the independent retail travel agent in an online world. The contradictory forecasts currently in circulation mean that the travel industry is a par-

\footnotetext{
*Correspondence to: Lisa Harris, Brunel University, Brunel Business School, Uxbridge, Middlesex UB8 3PH, UK.

E-mail: lisa.harris@brunel.ac.uk
}

ticularly interesting example of the disruptive impact of new technology. The Internet has provided opportunities for the major travel suppliers to target customers direct, thereby circumventing the traditional distribution channel through the travel agent. The paper begins by reviewing recent trends in the industry and changes in customer buying patterns. It then proceeds to examine the current mixture of 'bricks and clicks' in the industry and present arguments for and against the 


\section{The travel industry is a particularly interesting example of the disruptive impact of new technology}

ongoing viability of travel agents in this environment, drawing upon data from a wide range of sources. From this analysis the paper concludes that independent travel agents have a future, but they need to change their existing business models in response to the challenges of disintermediation. Specifically this requires appropriate investment in new technology, working closely with niche tour operators and creating competitive differentiation by focusing on specialist markets where core assets such as staff expertise can add value to the customer buying process.

\section{Metbodology}

The data has been obtained from a combination of secondary and primary sources including questionnaires, telephone interviews, personal experience of running both a tour operator and a travel agency, conversations at trade conferences and material from trade publications and governing organizations such as ABTA. Respondents provided a range of perspectives as they included sales staff at the customer interface right through to key industry leaders.

Furthermore, depth interviews were undertaken with the following companies to establish how some of the leading travel retailers viewed the impact of the Internet on the future of their existing retail outlets:

- STA Travel - a specialist niche player with 65 stores.

- Lunn Poly (owned by TUI, formerly the Thomson Group) - a mass-market travel agency with 800 stores.

- American Express - an upmarket travel agency with 25 stores.
- Bath Travel - a traditional family-owned agency based in SE England with 65 stores.

All of the companies surveyed had websites, however, Bath Travel was the only one without online transactional functionality. TUI was the only company to have any presence across more recent online platforms such as Digital TV and in-store kiosks.

The extent to which consumers are prepared to book holidays online or direct with tour operators is critical to the debate about the future of the travel agent, so this issue was considered by means of a 'pop up' questionnaire on the website of a specialist tour operator. There were 656 responses in December 2004. Customers who responded to the questionnaire were obviously prepared to at least check out potential holidays online, and so they were clearly not a representative group of society as a whole. However, the large number of responses obtained meant that this method provided valuable additional input to the research.

\section{Industry background}

The majority of UK travel agents belong to the Association of British Travel Agents (ABTA). ABTA's primary role is to provide consumers with financial protection should one of its members cease trading. All members have to provide adequate financial guarantees to ABTA, most commonly in the form of a bond. The ABTA logo is widely recognized by consumers and research conducted by MORI (2002) found that awareness of the ABTA brand was around $88 \%$. According to ABTA, 2004 was a particularly challenging year for its members due to global issues such as terrorism and the continued advancement of new technology. ABTA agents still represent approximately $80 \%$ of all package holidays sold in the UK, and its members employ over 110000 staff. ABTA has recently come under criticism from its membership for not doing enough to protect them from the threats of low cost airlines and commission cuts from tour operators. 
The UK retail travel market is highly competitive, with over 6000 retail travel agents that have ABTA membership and over 1000 others who belong to competing organizations with their own bonding structure. For many years the travel agent was seen as an important ingredient, adding value to the distribution process. Over 20 years ago, independent travel agents made up almost $90 \%$ of sales, until the leading operators decided that their future strategies would be best served by owning and controlling all of the components of the distribution channel such as hotels, airlines and travel agents. The outcome was that most of the independent travel sales were redistributed to these vertically integrated companies, and they increasingly took control over supply and distribution. In effect this was the start of the disintermediation process, which accelerated with the emergence of the Internet as a cost-effective distribution channel. The major tour operators can now sell their products more quickly and cheaply by going direct to the consumer electronically. At the same time they can develop deeper and lasting customer relationships. The potential of disintermediation is a real threat to the thousands of independent travel agents as their traditional business model is based on commission received from tour operators. Many of the major global airlines, including British Airways, have already significantly reduced, or in some cases eliminated, commission paid to travel agents.

New travel companies are using technologies to tailor or dynamically package travel products. Thomson (TUI) has announced plans to launch its own dynamic packaging tool. According to its Managing Director, Peter Rothwell, the traditional package holiday will continue to decline and dynamic packaging will be a major growth area for his company. He predicts that it will increase from current levels of $10 \%$ of UK sales to $35 \%$ by 2007 . David Elstob, Managing Director of Future Travel, is so confident in the rise of dynamic packaging that his company has more than doubled its ATOL bond for 2005 from $£ 19 m$ to $£ 48 \mathrm{~m}$. Of the $16 \%$ increase in sales turnover in
2004, over two-thirds were due to dynamic packaging (Huxley, 2004a).

Figure 1 shows the traditional distribution channels in the travel industry as recently as 2000 , and a possible scenario within a few years which shows that travel agents could be cut out of the loop altogether if they fail to adapt to the changes in the business environment.

\section{Changing customer buying patterns}

Internet access in UK households has risen from $9 \%$ in 1998 to $43 \%$ by 2003 (National Statistics, 2003a). Some $80 \%$ of households with a personal computer also have an active Internet connection (Oftel, 2003) compared with only $32 \%$ in 1999 . British Telecom (BT) signed up 250000 new customers to high-speed Internet access via its broadband services in September 2004 (Ashton, 2004). Mintel (2004) found that some $32 \%$ of people who had booked a holiday in the last 12 months had done so over the Internet, with total spending on all domestic and overseas travel breaking the $£ 50 \mathrm{~b}$ mark for the first time in 2003. This figure is almost double the 1993 expenditure of $£ 27.8 \mathrm{~b}$. It is, however, worth noting that there are still a significant number of people who do not have Internet access and these are people who could potentially be marginalized by businesses that focus on online channels. According to data from National Statistics (2003b), 39\% of adults never use the Internet and $57 \%$ have no significant need for or interest in it.

There have also been significant demographic shifts since the heyday of the package holiday in the 1970s. Married couples represented $64 \%$ of the population then but by 2003 this figure had reached $50 \%$. There are now more singles and the traditional family with 2.2 children is a thing of the past. This provides some evidence to explain changing customer requirements away from the typical package holiday and towards more independent travel. Many consumers are no longer satisfied with the one-size fits all package holiday and seek flexible products to suit their exact 

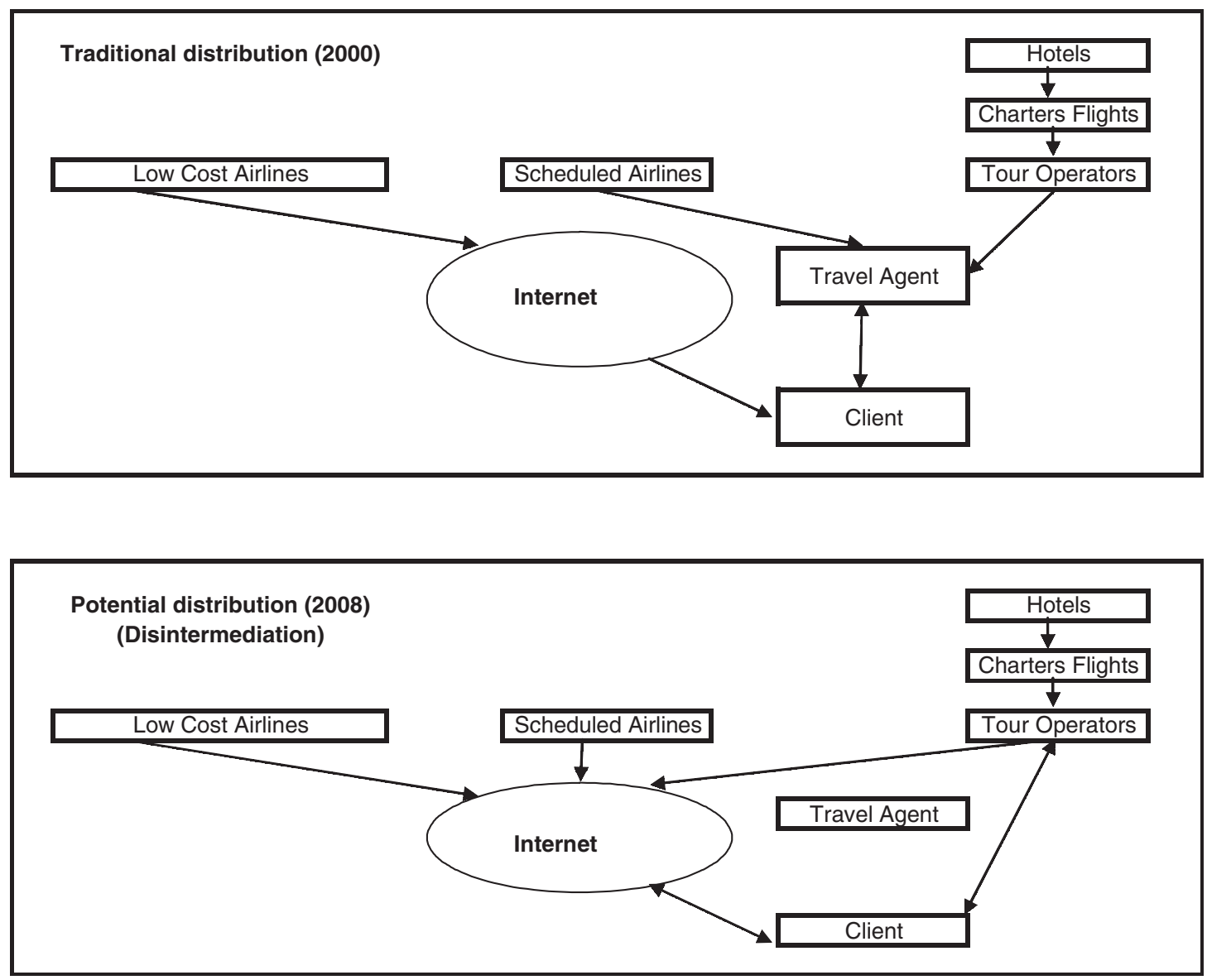

Figure 1. Traditional and prospective distribution channels in the travel industry.

travel needs. For example, the 'Greys' are a growing section of the UK population who are time and cash rich, with travel at the top of their expenditure priorities (Millennium Marketing, 2004).

The independent travel market in the UK has grown significantly in recent years and is now greater than the package holiday market. Mintel estimated that 24 million independent holidays ( $55 \%$ of the total market) would be taken in 2004. In 2003, independent holidays made up $38 \%$ of the total against 25\% who booked a package. An influential factor has been the growth of budget airlines such as EasyJet and Ryanair. Despite these findings the traditional package holiday still produces significant volumes. Ian Reynolds, ABTA Chief Executive (November 2004), estimates that 23 million people will take a dynamically pack- aged trip in 2005 but he also claims that the package holiday still has a future, with 19 million people planning such a trip. The package holiday by definition is a very pricecompetitive product appealing to the mass market. Whilst it does not have the flexibility of an independent holiday, it still fulfils the needs of a significant number of people who require a beach holiday for a fixed duration due to work or school commitments. However, sales are on the decline as 25 million people took a package holiday in 1995 .

\section{Bricks and clicks}

Drawing upon the model of online and offline channel options developed by De Kare Silver (2001), the majority of independent travel agents are still focused on storefront retailing. 


\section{The majority of \\ independent travel agents \\ are still focused on \\ storefront retailing}

Most have websites but very few have sophisticated online booking tools, although this situation is likely to change as the cost of the required technology falls. The major players, such as Thomas Cook, Lunn Poly, MyTravel and First Choice, aim to dominate all channels. Even Internet 'pure plays' such as Lastminute, Expedia and eBookers are now looking offline. Lastminute, for example, is building a retail presence through its recently acquired First Options brand. All of the companies interviewed for this research claimed that their online strategy was best described as integrated with their traditional business. No company suggested that it intended to move away from retail, and in fact both Bath Travel and STA predicted retail expansion.

There has been substantial media hype about potential shop closures as customers migrate online, but in fact currently the trend is for more retail outlets to be opened. Thomas Cook opened ten outlets in 2004 and First Choice opened five. The retail store has more value than simply serving customers - it also acts as an advertisement for the company's brand. Thomas Cook's new Managing Director, Steve Finlan, is investigating new methods for tracking sales across all the company's distribution channels. He believes that customers use the stores to pick up their brochures and whilst some store sales are falling, many customers now engage in 'mixed mode buying' and follow up a store visit by using one of the company's other distribution channels such as the call centre or website. Therefore, the store remains an important part of the distribution mix. Litsa Constantnou, Managing Director of STA Travel, announced that STA plans to open at least five new shops in the next 12 months, with growth mainly predicted in the South East (Nelson, 2004). STA Travel specializes in independent travel and its target market is the student and youth sector, a group well acquainted with using the Internet. This strategy would suggest that the retail store format has value and is some defence against disintermediation. It is a valuable first contact for customers, providing the convenience, expertise, security and reassurance that many online travel companies find difficult to deliver.

Thomson Holidays, on the other hand, whose primary market is traditional package holidays, is planning to close shops. O'Connell (2005) reports that 100 retail shops (branded as Lunn Poly) will close out of a total of 800. This will mean the loss of 2000 jobs as part of a major restructuring in the face of fierce competition from online retailers. The question addressed in this paper about the future of the travel agent is therefore particularly interesting, because here we see that one company whose target customers are high users of the Internet is growing its retail network, while the other whose core market is package holidays is actually closing shops, all within the same geographic area.

\section{The case for the viability of the travel agent}

Despite the hype surrounding online travel and the consequent demise of the travel agent, there has been a decline in the number of travel agency failures over the past 10 years according to the latest ABTA annual report for 2004. In 2004, 29 agencies went out of business compared with 31 in 2003 and 37 in 2002. Considerable evidence from the major players exists to suggest that the high street has a future. In addition to the example of STA Travel mentioned above, Harvey World Travel has an aggressive UK retailing strategy with plans to open some 70 UK stores in 2005 and build up to 170 by June 2006. It has already developed sophisticated software allowing its branches to dynamically package products for customers, and believes this is its key competitive advantage. Harvey World Travel is the largest franchise agency in the Southern Hemisphere, with over 360 branches in 
Australia. The company believes there is a profitable niche for an agent who can provide clients with flexible products in comfortable surroundings (Longman, 2004).

The 2004 Holiday Survey conducted by MORI for ABTA found that despite the move towards the Internet for holiday deals, over $70 \%$ of respondents trusted travel agents more than the technology and would be prepared to return to them if better deals were provided. When customers were asked to specify which methods they used to book holidays, the findings were as follows:

- $77 \%$ through a high street travel agent,

- $39 \%$ online,

- $25 \%$ direct with a tour operator,

- $14 \%$ teletext,

- $9 \%$ through a call centre.

These positive findings were also supported by Mintel research (July 2004), in which 64\% of respondents said they would still use a travel agent when booking a package holiday.

Preston Travel is a medium-sized tour operator specializing in travel to the Channel Islands. Although it can now transact directly with customers online, the company is still committed long-term to the travel agent for its primary source of income. Some $85 \%$ of Preston's holiday distribution is through the travel trade and over $60 \%$ of gross profit is repaid to travel agents in commission. Each year the commission negotiations begin with the agents seeking increased remuneration. Being a niche company without a strong consumer brand of its own, Preston has no choice but to agree otherwise its brochures simply would not be racked on the agents' shelves and those of a competitor would take their place. Preston currently pays travel agents up to $20 \%$ commission against the industry average of $10-12 \%$. In 2000 , a direct competitor, Travelsmith, tried to buck the trend by reducing the amount of commission paid to travel agents, but to date it has still not recovered from the lost sales. In 2001, Preston Travel re-branded a recent acquisition as a new low-cost brand called Jersey Travel Service.
This product was priced more aggressively than other Preston package offerings because it paid a lower rate of commission to the travel agent, and the savings were passed on to the customer. What happened in practice was that the travel agents directed customers towards the higher-priced Preston Holidays package in order to secure the greater commission, leaving Jersey Travel holidays unsold. This example supports claims by travel agents that they can influence which operator they book and hence should be a warning for other tour operators thinking of reviewing their commission strategy.

As noted earlier, retail travel agents provide convenience to customers and a strong brand can offer reassurance, especially versus online bookings where security is often cited as a key area of concern for consumers. High street travel shops also provide geographic awareness and brand recognition. According to Hugh Edwards, Former Director of TUI, every 100 prime high street travel shops are worth $£ 1 \mathrm{~m}$ per annum in advertising spend. He notes how a significant proportion of online bookings are for straightforward point-to-point travel, for example with low-cost airlines, and that consumers still prefer the services of an experienced travel agent for more complex bookings. A recent study by Co-op Travel (August 2004) challenged consumers to use the Internet to 'self-package' a holiday and concluded that the travel agent can source a cheaper holiday in less time. The study asked consumers and independent travel agents to find a holiday for a family or a break for two adults from various UK airports. The study found that agents took on average 15 minutes to source a package holiday versus an average 111 minutes spent by consumers searching the Internet for the same information.

Euro Travel is a good example of how a small privately run travel agent can leverage technology effectively in order to specialize and fight back against the threat of disintermediation. The business has been established for 22 years and launched its first website in 2000. It specializes in sales to only two European 
destinations, but has used the Internet as its primary communications channel in order to acquire customers from a broader geographic area, and has embraced new technologies that allow it to sell dynamically packaged travel. Sales turnover before web sales in 2000 was $£ 2 \mathrm{~m}$. In 2004 sales were $£ .6 .5 \mathrm{~m}$ and they are projected to reach $£ 8.5 \mathrm{~m}$ in the next financial year. Profits last year were in excess of $\$ 500000$.

This section of the paper has demonstrated that travel agents still have a number of opportunities to provide ongoing added value to customers in terms of convenience, flexibility through dynamic packaging, security and expertise. Through face-to-face customer interaction in this environment they are in a strong position to influence the customer's choice of holiday to their own best advantage, at least as far as the smaller tour operators are concerned. However, there are a number of counter-arguments to which we will now turn.

\section{The case against the viability of the travel agent}

If customers continue to interact with holiday suppliers online then the future of the travel agent looks uncertain, especially if the tour operators have sufficient market strength to reduce agent commission. Commission remains the lifeblood of the travel agent and the single biggest expense for the supplier. Many tour operators are looking at cutting the commission they pay to travel agents in the same way the airlines have done over the last few years, and are using other low-cost distribution channels such as the Internet to go direct to customers. Thomson Holidays, the largest tour operator in the UK, has announced plans to cut commission on seatonly sales in order to compete on price with budget airlines, and that on web bookings made through agents from $10 \%$ to $7 \%$ (Huxley, 2004b). Thomson are also about to announce the launch of their own accommodation booking website to compete with the many online accommodation companies, and they will pay zero commission to travel agents on these products. British Airways was the first UK airline to cut commission to the retail trade - initially to just $1 \%$, and then eliminated completely in 2005. According to BA Chief Executive Rod Eddington, 'BA does not owe agents a living' (Coulter, 2004). Whilst he recognizes the value of the agent, he believes their remuneration should be achieved through service fees.

Several reports have identified the Internet as the preferred channel for making travel enquiries and online holiday bookings. The 2004 Holiday Survey conducted by MORI for ABTA, found that the Internet is now firmly established as a booking tool for holidays. According to this survey, $19 \%$ of holidaymakers now book their package holiday online six times the number that were doing so in the year 2000. MORI research commissioned for ABTA (November 2004) found that even if travel agents had superior knowledge and provided individual service, once consumers had tried using the Internet they will continue to do so. According to Thomas (2004), package holidays through travel agents will continue to drop by $4 \%$ in 2005 following a $6 \%$ drop in 2004. He points out that package holiday sales are now at their lowest levels since 1993 at $52 \%$ of all bookings, whilst online transactions look set to rise to $13 \%$ of all bookings next year.

The value of independently booked holidays is set to increase by almost $80 \%$ to more than $£ 21 \mathrm{~b}$ in 5 years, according to Mintel. They also estimate that the UK expenditure on independent holidays has more than doubled from $£ 5.5 \mathrm{~b}$ in 1998 to $£ 11.7 \mathrm{~b}$ in 2004. Mintel believes that the increased popularity of independent holidays owes almost everything to the Internet, indicating that the greater use of the Internet has simplified the entire process for the independent traveller. Most significantly, independent holidaymakers used the Internet more than any other method when purchasing the holiday (Mintel, November $2004)$ with some $40 \%$ of people making their arrangements on the Internet versus $27 \%$ who used a travel agent. 
Another potential threat to the travel agent is the increased number of consumers going direct to tour operators, either because they believe they will get a better price or that the operators can provide more or better information. There is a danger that travel agents are increasingly becoming brochure collection points, especially as most tour operators now advertise their web address and direct telephone numbers on the brochure. The findings of the online questionnaire posted on a tour operator website were that over $27 \%$ of customers would still prefer to book through a travel agent but 38\% would book direct with a tour operator. On using the Internet for actual bookings or information, $37 \%$ said they would use it to research information and $48 \%$ said they would also be prepared to book and pay online. According to a study of 722 independent travel agents (Smallman, 2004), 35\% of agents feared tour operators were encouraging customers to book direct but only $8 \%$ were concerned about the possibility of commission cuts.

This section of the paper has shown that travel agents are threatened by the increasing tendency of customers to book holidays directly with a tour operator, or to arrange their own independent holidays rather than a traditional package. In addition to the consequent decline in the numbers of holidays booked by agents, they also look likely to earn less commission on each transaction as the major tour operators and airlines tighten their belts.

\section{Discussion and conclusion}

The evidence presented here suggests that the way forward for travel agents is actually through a combination of Internet technology and specialization to provide customers with added value. By 'unpacking' the traditional package holiday product using the latest technology, travel agents are able to ' $\mathrm{mix}$ and match' a variety of suppliers from transportation to accommodation and combine these components into one selling price. For example, new technologies are now available which allow travel agents to book low-cost airlines and incorporate them into 'flexible' packages. This strategy has the potential to save the client money and time spent on searching the web themselves, increases the flexibility of the offer and provides a better income for the agent because it cuts out the tour operator's margin on the products sold.

The greatest fear of the independent travel agent is disintermediation, whereby the tour operator sells direct to customers and removes the agent altogether. The Internet is providing the major tour operators and customers with opportunities for direct interaction. Travel agents can either stand by and watch this happen or take real decisive action by investing in dynamic packaging technology and providing added value services to key customer groups. The companies that have achieved above-average performance are those that focus on the independent travel sector or that have chosen a specific niche in which to specialize, for example, Flight Centres and STA Travel. STA has virtually lost its European travel business, but continues to grow by focusing on long-haul, more complex itineraries that are beyond the reach of low-cost airlines. Whilst embracing the Internet for marketing purposes, the company's products are of a complex nature so that it requires an experienced sales person to service client needs effectively. Not surprisingly, these organizations still intend to expand their retail networks.

However, to embrace the opportunities of dynamic packaging, independent travel agents will require a higher level of bonding (ATOL). Secondly, they will need to make significant investment in technology and marketing. It is doubtful if many will have the resources or long-term commitment in making such investments and certainly the future is not for the faint-hearted. In addition, even though dynamic packaging presents exciting opportunities for travel agents it is not the solution many people believe it to be. It should be seen as complementary to selling package holidays because small independent agents will never have the buying power of the vertically inte- 
grated operators who control the transport and in some cases accommodation, and the infrastructure such as transfers and overseas representation.

Of all the major vertically integrated travel companies in the UK, one of the most successful in terms of profit is First Choice, which has differentiated through market segmentation. Chief Executive Peter Long made a strategic decision to move away from the mainstream short-haul market and focus on long-haul and specialist markets, especially in the growing independent sector. His strategy appears to have paid off, while short-haul sales were down $19 \%$ for winter 2004/5 and down $4 \%$ for summer 2005 , medium-haul sales were up $13 \%$ for $2004 / 5$ and $30 \%$ for summer 2005 , with long-haul sales up $57 \%$ for 2005 . Revenues in activity and specialist holiday sectors are up $10 \%$ for 2005 . The lesson here is that travel companies should consider developing niche products for selected target markets within their overall product offering.

Independent travel agents should also consider working more collaboratively with niche tour operators so that both parties can benefit financially from the arrangement. If independent travel agents start to lose package sales, they can turn to a number of smaller niche tour operators who rely on the travel trade for the majority of their business. To get brochureracking space on the high street, these niche companies need to pay agents attractive rates of commission and are not in a strong enough position to dictate to the trade, as indicated in the Preston Travel example. We can also look to the USA for some guidance as to what the future holds. Travel agents in the USA have been working with no commission for several years now and still many survive and indeed thrive.

A note of caution is required for major travel companies trying to reinvent themselves as low-cost businesses in order to compete with online travel companies such as Lastminute and Expedia. Despite the hype surrounding these companies, they are still struggling to make a profit. Most of their top-line growth has been achieved through the acquisition of tra- ditional offline travel businesses. According to Lastminute Chief Executive Brent Hoberman, trading remains challenging and whilst the business is achieving higher volumes, much of it is price-driven resulting in low margins (Clarke, 2004). The company is targeting $£ 16$ m savings for 2005 mainly through job losses (350) and the closure of ten offices. Its share price has also fallen substantially.

In summary, it is clear that despite advances in technology, traditional marketing principles of differentiation and segmentation still hold true. In common with many other sectors of the economy, the Internet appears to be complementing rather than replacing existing business priorities in the travel industry.

\section{The Internet appears to be complementing rather than replacing existing business priorities in the travel industry}

The research presented here indicates that sales of dynamically packaged products will grow at the expense of package holidays, although the latter will still represent a significant aspect of the overall travel business. It is also evident that the Internet will continue to grow as a travel information source and that online bookings will increase as more people have access to high-speed Internet connectivity. Closer collaboration between tour operators and agents to provide innovative and value-added services through effective use of information technology and staff expertise is recommended to prevent the customer from 'going it alone'. While this paper has focused on the industry implications of technological change, future research will be undertaken to examine in more detail the critical role played by people in creating a sustainable competitive advantage through a combination of industry expertise and effective utilization of information technology, to repackage holiday products in creative ways. 


\section{Bibliographical notes}

Lisa Harris (lisa.harris@brunel.ac.uk) has 10 years' industry experience in retail banking and now lectures in marketing at Brunel University, West London.

Kevin Duckworth (Kevin@ptgh.co.uk) is a travel industry professional with over 25 years' senior management experience in both retailing and tour operating.

\section{References}

Ashton J. 2004. High speed BT gets a big boost from broadband. Daily Mail, 13 October, p. 12.

Clarke M. 2004. Lastminute tightens belt with UK job cuts. Travel Weekly, 8 October, p. 10.

Coulter J. 2004. BA doesn't owe agents a living. Travel Trade Gazette, 30 July, p. 5.

De Kare Silver M. 2001. e-Shock: The New Rules Palgrave: Basingstoke.

Huxley L. 2004a. DIY boom is key to future growth. Travel Trade Gazette, 24 December, p. 1.
Huxley L. 2004b. Thomson cuts hit agent income. Travel Trade Gazette, 10 December, p. 1.

Longman L. 2004. It's a good day for the high street. Travel Weekly, 29 October, p. 1.

Millennium Marketing. 2004. Annual Report, November.

Mintel. 2004. Independent Travel.

National Statistics. 2003a. Internet Access: Housebolds and Individuals. National Statistics: London.

National Statistics. 2003b. Internet Connectivity. National Statistics: London.

Nelson P. 2004. Five new shops planned. Travel Weekly, 29 October, p. 20.

O'Connell D. 2005. TUI to cut 2000 staff in major restructuring. Sunday Times, 27 March, p. 4.

Oftel. 2003, Consumer Use of the Internet. Oftel Residential Survey: Q13. Office of Telecommunications: London.

Smallman C. 2004. Independent agents fear the pain of DIY. Travel Trade Gazette, 2 July, p. 24.

Thomas S. 2004. Package sales drop to lowest in 11 years. Travel Weekly, 17 December, p. 1. 